\title{
Need Assessment for an Adolescent Clinic in a Periurban Hospital
}

\author{
S TASNIM
}

\begin{abstract}
:
Background: Adolescents are a heterogeneous group with special reproductive health needs based on their age, sex, marital status and socioeconomic status. Existing health care system is not capable to respond to adolescents'demands.

Objective: To explore the idea regarding specific centre for adolescents and to identify the components of information and health services rendered through the centre.
\end{abstract}

Method: A cross sectional study was conducted with 70 participants in a half day workshop in the Institute of child and mother health (ICMH) on $9^{\text {th }}$ August' 2006. The respondents filled up a set questionnaire containing both open and closed questions focusing different issues regarding functioning of an adolescent clinic. The responses were analysed using SPSS program

Result: Almost all respondents expressed the need for a separate clinic for adolescents, that should serve both boys

\section{Introduction:}

Adolescents are between 10 to 19 years and in a transition of physical, mental and social development towards adulthood. They have special needs that will vary with their sex, stage of development, life circumstances and the socioeconomic condition of their environment ${ }^{1}$. Adolescents begin to experience new ideas, relationships and life styles. As they mature they are increasingly exposed to reproductive health risks such as sexually transmitted infections, unintended pregnancies and complications from pregnancy and childbirth $^{2}$. It is necessary to provide care and support to them to cope up with the changes. They need proper guidance to become knowledgeable, confident and skilled to overcome the problems and develop as adults International Conference on Population Development (ICPD) declaration states that countries must ensure that the programs and attitudes of health care providers do not restrict the access of adolescents to appropriate services and the information they need, including sexually transmitted diseases and sexual abuse. These services must safeguard the rights of adolescents to

Address of correspondence : Dr. Saria Tasnim, Associate Professor, Gynaecology \& Obstetrics, Institute of child and Mother Health

Received: 28 April, 2010

Accepted: 29 December 2010 and girls (84.3\%), health providers at the centre should be doctors from both Paediatrics and Gynae \& Obstetrics department (42.9\%) and nurses (42.1\%) and the working schedule should be similar to existing out patient hours. It was suggested that the clinic should provide counseling on sexuality issues, contraceptive services and special services as required in addition to general health care. About $75 \%$ opined that the cost of the services should be same as those of existing out patient services while $52.9 \%$ thought that the services should be free.

Conclusion: The need for an adolescent clinic was commonly felt and it is recommended to establish adolescent friendly services at ICMH.

Key words: Adolescent, Reproductive health, Adolescent friendly service

(J Bangladesh Coll Phys Surg 2011; 29: 133-137)

privacy, confidentiality, respect and informed consent, respective cultural values and religious values ${ }^{3}$.

In traditional society of Bangladesh sexuality is regarded as a private matter and often deliberately ignored to be discussed. It is difficult to obtain information on sexual behavior and practices specially those of unmarried adolescents. However, knowledge gap on reproductive health issues among adolescent was revealed in different studies $^{4-7}$. As a consequence of the ignorance, adolescents may fail to protect themselves from unwanted and unsafe sexual practice ${ }^{5}$. It is well known that adolescents have limited access to reproductive health information and services ${ }^{8,9}$. However, parents, religious and other community leaders supported the idea of reproductive health education in the school curriculum $^{8}$. The adolescent themselves express the need to include reproductive health information in the school curriculum ${ }^{6,10}$.

Adolescent reproductive health represents an area of tremendous unmet need worldwide. Existing health care system usually defers to respond to the reproductive health need of adolescent as social entity. They frequently fail to provide adolescents with specialized reproductive health information, counseling and services ${ }^{1}$. Lack of experience in social negotiation , 
ignorance about their bodies and where to seek care, social stigma and poor treatment by providers often limit young peoples' access to services they need ${ }^{11}$. An adolescent's clinic is such that will attract, serve and retain adolescents for reproductive health needs ${ }^{12}$.

A need assessment survey was done to explore the idea regarding a specific health centre for adolescents, to identify specific information and service areas and options for its implementation.

\section{Method:}

This was a cross sectional descriptive study with 70 participants conducted at Institute of Child and Mother health (ICMH). A half day workshop was arranged on 9th August '2006 where faculty members and junior doctors of Obstetrics \& Gynecology, Paediatrics and allied specialty of ICMH participated. At the beginning a presentation was made by the researcher addressing a brief overview of adolescent reproductive health, characteristics of adolescent friendly services and gaps in providing the services. The potentials of establishing an adolescent clinic at ICMH was discussed in the workshop. The respondents filled up a self administered questionnaire consisting both open and closed questions focusing different issues regarding functioning of an adolescent clinic. Opinion of some nurses and adolescents were also collected through same questionnaire in a separate session. The responses were analysed using SPSS program.

\section{Result:}

The respondents were faculty members (12), junior doctors (28), nurses (20) and adolescents (10). The need for an adolescent clinic at the institute was expressed unanimously. They opined that it should serve both boys and girls (84.3\%), remain open 6 days a week (54.3\%), and (47.1\%) said working hour should be same as the existing outdoor schedule (Table-I). Nearly half of them (42.9\%) said that doctors from both Gynae and Paediatrics department and nurses should serve in the clinic (Figure-1).

Majority suggested that the clinic should provide general health care, pregnancy related care, counselling and communication on sexuality issues and $55.7 \%$ said that there should be provision for distribution of condoms (Table-II). Counseling topics as expressed were physiological changes of puberty, contraception, sexually transmitted infections, consequences of early marriage and pregnancy, substance abuse and adolescent rights (Table-III). To promote use of the clinic it was recommended to arrange health camps in local school and colleges (92.9\%), distribution of leaflets (82.9\%),
Others include Nutritionist, psychologist, Counselor, and Specialist Doctor

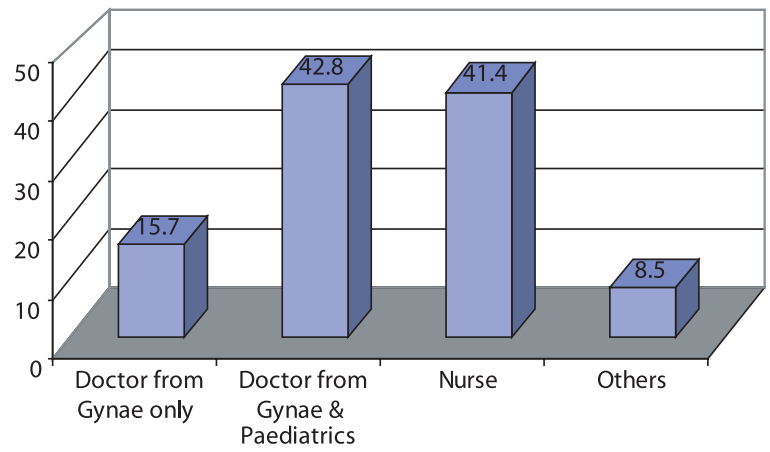

Fig.-1: Percent distribution according to opinion regarding who should provide services in the adolescent clinic $(n=70)$

and (71.4\%). suggested making signposts in the hospital (Table-IV). Major constrains for establishing the clinic were shortage of manpower (47.1\%), adolescents' unwillingness to attend the clinic (41.4\%) and $47.4 \%$ thought it will be an extra burden for health care providers (Figure-2). About $75 \%$ opined that cost of services should be in accordance with the existing system of payment at outdoor, while $52.9 \%$ and $34.2 \%$ thought the consultation and any service required should be free respectively (Table-V).

\section{Table-I}

Distribution according to opinion regarding the characteristics of adolescent clinic in terms of providing services $(n=70)$

Characteristics

Percentage

Beneficiaries at the adolescent clinic

Adolescent boys only

Adolescent girls only

15.71

Both

84.28

Days the clinic should work in a week?

One

Two

24.28

Daily (Six days)

54.28

For how many hours the clinic should work in a day?

Same as existing OPD hours $\quad 47.14$

2 hours in a day

11.42

4 hours in a day

What should be the timing of the clinic?

Same as existing OPD hours

58.57

From 9-11 am

21.42

From 11-1.00 pm

5.7

From 2-3 pm 
Table-II

Distribution according to opinion regarding type of services that should be provided in the clinic* $(n=70)$

Characteristics

Percentage

\begin{tabular}{ll}
\hline Measurement of height & 94.28 \\
Measurement of weight & 91.42 \\
Clinical examination for anaemia/ malnutrition & 94.28 \\
T. T immunization & 94.28 \\
Distribution of anthelminthic & 84.28 \\
Antenatal care & 85.71 \\
Postnatal care & 84.28 \\
Reproductive health education session & 91.42 \\
Post abortion care & 84.28 \\
Treatment of infection and diseases & 82.85 \\
Contraceptive advise & 84.28 \\
\hline
\end{tabular}

Table-III

Distribution according to opinion regarding counseling issues in the clinic $(n=70)$

\begin{tabular}{lc} 
Characteristics & Percentage \\
\hline Physical change during Puberty & 98.57 \\
Mental changes during adolescence & 91.42 \\
Menstruation & 100 \\
Masturbation & 75.71 \\
Night emission & 78.57 \\
Conception & 94.28 \\
Contraception methods/ Emergency & 88.57 \\
contraception & \\
Violence & 82.85 \\
Sexually transmitted infection \& HIV/ AIDS & 98.57 \\
Substance abuse (Cigarette, alcohol, drugs) & 85.71 \\
Danger sign of pregnancy & 100 \\
Consequences of early marriage and & 95.71 \\
adolescent pregnancy & \\
Adolescent rights & 82.85 \\
Nutrition & 87.14 \\
General hygiene & 98.57 \\
Sign symptoms of pregnancy & 87.14 \\
Others (ideal marital age etc) & 31.42 \\
\hline
\end{tabular}

*Multiple response

\section{Table-IV}

Distribution according to opinion regarding measures to be taken to increase the utilization of the clinic $(n=70)$

\begin{tabular}{lc} 
Activity & Percentage \\
\hline Making sign posts in the hospital & 71.42 \\
$\begin{array}{l}\text { Arranging health camps in adjacent } \\
\text { schools/College }\end{array}$ & 92.85 \\
$\begin{array}{l}\text { Arrange a rally } \\
\text { Distribution of leaflet to parents, }\end{array}$ & 51.42 \\
$\begin{array}{l}\text { school teachers } \\
\begin{array}{l}\text { Others (Give monthly magazine, extension } \\
\text { of the clinic subsequently, adverting }\end{array}\end{array}$ & 37.14 \\
in media.) & \\
\hline
\end{tabular}

*Multiple response

\section{Table-V}

Distribution according to opinion regarding the financial implication of its services $(n=70)$

Cost of services at the clinic

Consultation should be free

Existing system of paying for OPD

tickets \& Pathology

Iron, Folic Acid, Anthelminthic

should be free supply

Any service required should be

free of cost

*Multiple response

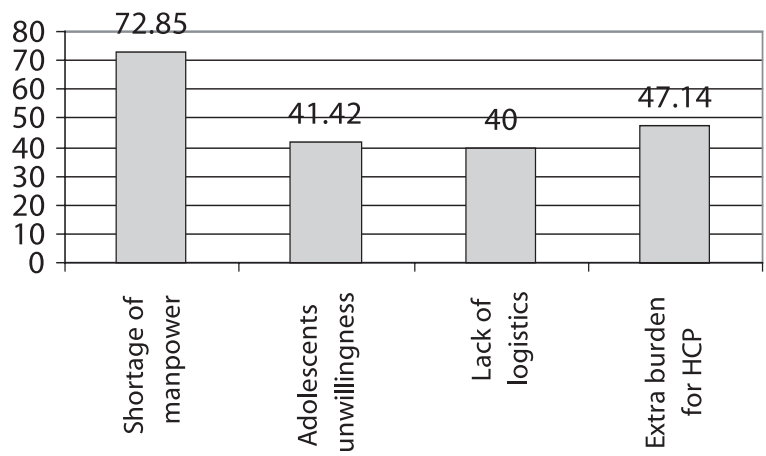

Fig.-2: Percent distribution according to opinion regarding the limitations in establishing the clinic 


\section{Discussion:}

It was evident from this study that health care providers were well aware that adolescents are a special group and the need of separate provision to serve them was

commonly felt. The idea of establishing an adolescent clinic in the outpatient department was well accepted and it was opined that both adolescent boys and girls should be served and doctors and nurses from multiple discipline should provide counseling and treatment according to individual needs through the special clinic. In another study the need of special clinic where adolescent can get information and service is a highly demanding issue that has been expressed by the adolescents themselves and their teachers ${ }^{10}$.

Use of such adolescent clinics by the adolescents depends on various factors. Evidence shows adolescents avoid seeking reproductive health services unless confidentially is assured ${ }^{13}$. It is also that they do not want to expose their reproductive health problems in front of others such as in polyclinics where services are tailored to adults ${ }^{14}$. In a study from South Africa the young respondents expressed that the most important factor influencing their choice of a clinic were staff attitude, clinical environment, availability of the contraceptive methods and operating hours ${ }^{13}$. Study have revealed that adolescents are reluctant to use health centers because there are long waiting time, often the providers are rude, judgmental and do not show respect for adolescents privacy and confidentiality ${ }^{15}$.

In this study the health care providers and the adolescents has opined to utilize existing policy of cost recovery and timing of out patient services that need to be evaluated for feasibility after implementation. Some non government organization that provides adolescent friendly services tailors their timing as per convenience of school going or working adolescents. For example, Marie stopes society runs youth friendly health clinics that accommodate adolescents separate from adults, logs and records are kept separately and adolescent specific hours are daily after normal clinic hours, generally from 4.00 to $6.00 \mathrm{p}, \mathrm{m} .{ }^{16}$. Under a global fund project that aims to promote involvement of youth for prevention of HIV and AIDS Government of Bangladesh has established youth friendly corners in different district hospitals and Maternal and child welfare centres that use normal out patient hours ${ }^{17}$.
Shortage of manpower was identified as a main constraint for adolescent friendly services in this study and that was an appropriate concern. According to the national standard the providers of adolescent friendly services must have good interpersonal and communication skill, motivated to work with adolescents, supportive, non-judgmental and devote adequate time to patient ${ }^{18}$. So capacity building of health care providers is also a prerequisite before establishing the clinic. There is evidence that training of health care providers on youth friendly services helped them to inform adolescents about where to obtain the health care services and can also convince them that services were more geared towards their needs ${ }^{19}$. Although it was a small scale study but it involved different levels of health care providers and also the potential users that is the adolescents and their recommendations will be utilized to formulate an action plan for establishment of an adolescent clinic.

\section{Conclusion:}

The need for a separate service corner for adolescents was commonly felt by the health care providers as well as the beneficiaries. Specific issues for counseling and type of services to be provided through an adolescent clinic was also suggested. .It is recommended that an adolescent clinic should be established at ICMH according to the need assessment.

\section{References:}

1. WHO. Orientation program on adolescent health for health care providers. 2003

2. Virginia Morell. Attacking the causes of silent infertility. Science 1995; 269 (5225): 775-76

3. United Nations. Program of action adopted at the international conference on population and development. Cairo 5-13 September 1994.New York

2. Virginia Morell. Attacking the causes of silent infertility. Science 1995; 269 (5225): 775-76

3. United Nations. Program of action adopted at the international conference on population and development. Cairo 5-13 September 1994.New York

4. Haider SJ, Nahar SS, Kamal N, Gray A. Study of Adolescents; Dynamics of perception, attitude knowledge use of reproductive health care, 1997, Population Council

5. Rob U, Bhuyia I, Improving adolescent reproductive health in Bangladesh. Research update no: 1, 2001. Dhaka Bangladesh. Population Council

6. Halida Hanum Akhter, M M Hossain, Mohsena Akter, Shalini ND, Hafizur Rahman. Report on needs assessment on 
reproductive health information and care among adolescents in paurashava school and college. BIRPERHT. December 2000. Dhaka.

7. Saria Tasnim, PC Barua, AKM Shahabudin, Baseline survey on reproductive Health and Care seeking behaviour sexual problem among the adolescent girls. Final report 2002, Dhaka.

8. Rob U, Bhuyia I, Rahman L, Yusuf N.. Improving adolescent Reproductive health in Bangladesh. Research update no: 2, 2002. Dhaka, Bangladesh. Population Council

9. Barkat A, Majid M, Adolescent Reproductive Health in Bangladesh; Status, Polices, Programs and Issues, Report for the POLICY project, July- 2002

10. Saria Tasnim, Aminur Rahman, Iffat Ara. School based sexuality education for adolescents, Final report 2005. Institute of Child and Mother Health and Ministry of Science, communication information technology, Dhaka.

11. Liz C Creel, Rebecca J Perry. Improving the quality of reproductive health care for young people. New perspectives on quality of care:no4. Population refernce bureau 2003

12. Senderowitch J, Hainsworth G, Solter C. A rapid assessment of youth friendly reproductive health services Technical guidance series no 4. 2003. Pathfinder International

13. Dominique Meekers anbd Megan Klein. Determinants of condom use among young people in urban Cameron. Studies in Family Planning 2002; 32 (4):336-46
14. WHO. Adolescent friendly health service. An impact model to evaluate their effectiveness and cost. 2002.

15. Gans SE, Mc manus MA, Newo check Pw, Adolescent health care: use , cost, and problems of acces. VZ, Cichago : American medical association , 1991.

16. Nahar Q, Tunon C, Howveras I, Rukhsana G, Reza M, Huv, NL, Barket e Khuda. Reproductive health needs adolescents on BD: a study report. Dhaka: ICDDRB, 1999. (ICDDRB working paper no 130).

17. Rikka Transgrud. Adolescent Reproductive health in East and Southern Africa: building experience, four case studies. 1998. Family care International

18. Save the Children USA, Report on assessment of reproductive and sexual health needs of adolescents Bangladesh field office July 2003, Dhaka.

19. GOB. National Standards for adolescent friendly health services in Bangladesh. Generic Characteristics of adolescent friendly health services within WHO defined dimension of Quality. April, 2005.

20. Marie Stopes newsletter, 2007

21. Project on prevention of HIV/AIDS among youth and adolescents in Bangladesh (GF902) Collaborative project between MOHFW \& Save the Children USA. Presentation on workshop on ensuring youth friendly services. December 12-15 2004, Dhaka.

22. Engender Health. Youth friendly services: A manual for service providers 2002 New York 